\title{
Decompressive Craniectomy (DC) - Comparative Study of 30-Day Mortality in Surgeries of Severe Brain Trauma with Subdural Hematoma, with and without DC
}

\section{Craniectomia descompressiva (CD): estudo comparativo da mortalidade em 30 dias das cirurgias para traumatismo craniano grave com hematoma subdural, com e sem $C D$}

Lucas Eduardo Bonadio ${ }^{1}$ Luis Renato Garcez Mello ${ }^{1}$ Leandro Jose Haas ${ }^{1}$ Vitor Hugo Tamiosso Boer ${ }^{1}$ Celso Itiberê Carvalho Bernardes ${ }^{1}$ Danielle De Lara ${ }^{1}$ Filipe Laurindo Cabral ${ }^{2}$ Gabriel Hoher Peres ${ }^{2}$ Stephanie Lindner ${ }^{2}$

\footnotetext{
${ }^{1}$ Neurosurgeon, Department of Neurosurgery, Instituto Catarinense de Neurologia e Neurocirurgia, Hospital Santa Isabel, Blumenau, SC, Brazil

2 Department of Neurosurgery, Hospital Santa Isabel, Blumenau, SC, Brazil
}

Arq Bras Neurocir 2017;36:21-25.
Address for correspondence Lucas Eduardo Bonadio, MD, Instituto Catarinense de Neurologia e Neurocirurgia, R. Mal. Floriano Peixoto, 300, Centro, Blumenau, Santa Catarina, Brazil 89010-500 (e-mail: lucasbonadio@hotmail.com).

\begin{abstract}
Keywords

- decompressive craniectomy

- acute subdural hematoma

- mortality

Objective Compare 30 days mortality of patients harboring acute subdural hematomas in two series, one treated only by wide aspiration of hematoma and other with aspiration followed by decompressive craniectomy.

Methods Comparing retrospectively two series of ASD with and without DC. Involved 81 TBI patients with acute subdural hematoma and GCS $\leq 8$ (Jan 2000 to Nov 2014) arranged into two groups. Group 1 - 58 cases underwent to DC. Group 2 - 23 patients underwent only hematoma aspiration.

Results Group 1 showed $44.8 \%$ mortality directly due to brain lesion within 30 days. The most frequent associated lesion were contusion in 37.2\%. Group 2 the mortality within 30 days was $47.8 \%$. The majority of deaths $(82 \%)$ resulted from uncontrollable brain swelling, midline shift was present in $94.7 \%$ of patients.

Conclusion High admission GCS and age less than 50 remain better outcome predictor in 30 days survival for patients undergoing surgery of traumatic ASDH.
\end{abstract}

received

August 14, 2016 accepted

October 13, 2016

published online

December 19, 2016
DOI http://dx.doi.org/ 10.1055/s-0036-1596050. ISSN 0103-5355.
Copyright (e 2017 by Thieme Revinter

Publicações Ltda, Rio de Janeiro, Brazil
License terms

(ㄷ) (i) $\ominus$ (\$) 


\section{Resumo}

Palavras-chave
- craniectomia
descompressiva
- hematoma subdural
agudo
- mortalidade

Objetivo Comparar a mortalidade em 30 dias de pacientes que sofreram hematoma subdural agudo em duas séries, uma tratada por aspiração do hematoma e outro por aspiração seguida de craniectomia descompressiva.

Métodos Comparar retrospectivamente duas séries de HSD com e sem CD. Envolveu 81 pacientes com TCE com hematoma subdural agudo e GCS $\leq 8$ (Jan 2000 a Nov 2014) em dois grupos. Grupo 1-58 casos tratados submetidos a CD. Grupo 2-23 pacientes submetidos a drenagem do hematoma somente.

Resultados Grupo 1 apresentou 44,8\% de mortalidade diretamente devido a lesão cerebral dentro de 30 dias. A mais comum lesão associada era contusão em $37,2 \%$. Grupo 2 a mortalidade dentro de 30 dias foi $47,8 \%$. A maioria dos óbitos (82) resultou de edema cerebral incontrolável, desvio de linha média estava presente em $94,7 \%$ dos pacientes.

Conclusão Alto GCS de admissão e idade menor que 50 anos permanecem melhores preditores de desfecho na mortalidade em 30 dias para paciente submetidas a cirurgia de hematoma subdural agudo.

\section{Introduction}

Despite current advances, the mortality rate by severe traumatic brain injury (TBI) is still $\sim 30 \%$ after six months without reasonable improvement of morbidity. Aggressive measures have been advised for controlling those bias, like bilateral decompressive craniectomy, wherein decompressive hemicraniectomy is the most popular procedure in the database about TBI. ${ }^{1-3}$

An increasing number of reports on the prognosis for TBI after decompressive craniectomy have been published, focusing on several intracranial lesion long-term outcomes. The most important mass injury in TBIs is subdural hematoma, generally accompanied by ipsilateral swelling, midline shift and thickness of hematoma. The indication of hematoma drainage with or without decompressive craniectomy $(D C)$ is a challenge that has not yet been definitively established. ${ }^{4-6}$

The enthusiasm for DC has been motivated by the results of a recent multicenter prospective randomized trial of early decompressive craniectomy in patients with severe traumatic brain injury (DECRA) study, which showed a more unfavorable outcome following DC. The results cannot be extrapolated to patients with focal or mass lesions. Decompressive Craniectomy should not be considered a risk-free procedure due to complication rates of up to $50 \%$. In this article, we report a comparative 30-day mortality of patients harboring acute subdural hematomas (ASHs) in two series, one treated only by wide aspiration of the hematoma, and the other with aspiration followed by DC. ${ }^{6-12}$

\section{Material and Methods}

The study involved 81 TBI patients with ASHs who were admitted to Hospital Santa Isabel between January 2000 and November 2014. All patients were assessed according to age, gender, Glasgow Coma Scale (GCS) score at admission, associated systemic injury (hypoxia and hypotension), pu- pillary reactivity, midline shift; associated intracranial injuries; and timing for DC and Glasgow Outcome Scale (GOS) score.

The patients were divided into two groups. Group 1 consisted of 58 cases treated between January 2007 and November 2014 with DC, and group 2 consisted of 23 patients treated between January 2000 and December 2006 who underwent only hematoma aspiration by a wide craniotomy followed by eventual dural expansion and reposition of bone. The patient selection criteria for the study were presence of subdural hematoma, and a GCS score of 8 or below, regarded as "severe head injury," evaluated after the primary resuscitation at the emergency service.

Comparisons between both groups were made using the Chi-square test. Differences were considered significant when $p<0.05$.

\section{Results}

Group 1 involved 58 patients, with a mean age of 40.9 (13-77 years.); $81 \%$ of them were male. A total of $82.6 \%$ of these patients presented at admission a midline shift of more than $5 \mathrm{~mm}$. Mortality directly due to brain lesion within 30 days was $44.8 \%$ (26 cases). Three patients died of lung infection after 30 days. Fourteen patients had 2 reacting pupils just before the craniotomy (24.1\%). Anisocoria with only 1 reacting pupil was found in 33 cases (56.8\%), and both pupils were not reacting in 11 patients (18.9\%). A computed tomography CT scan showed that the most frequent associated lesions were contusion (37.2\%), brain swelling (17.6\%) and multiple lesion (7.8\%); however, 33,3\% showed no associated injury.

Group 2 comprised 23 patients, 19 male and 4 female, with a mean age of 44 years (16-74 years). A pupillary examination identified 5 patients with 2 reacting pupils, 16 with 1 reacting pupil, and 2 with 2 non-reacting pupils. Before craniotomy, the mean GCS score was 5. Every patient underwent emergency wide craniotomy within 24 hours, with aspiration of the ASH and cortical veins hemostasis, 
without DC. A preoperative CT scan found a contusionassociated hemorrhage in $40.9 \%$, epidural hemorrhage in $9 \%$, and brain swelling in $18.1 \%$ of patients. The mortality within 30 days was $47.8 \%$ (11 patients). The majority of deaths (82\%) resulted from uncontrollable brain swelling and high increased intracranial pressure (ICP), which occurred in 1 patient with 2 reactive pupils, in 2 patients with 2 nonreacting pupils, and in the other 8 patients with only 1 reacting pupil. Midline shift was present in $94.7 \%$ of the samples, of which 15 patients presented associated cerebral lesions, causing 10 deaths, mainly due to high intracranial pressure caused by swelling and contusion (-Table $\mathbf{1}$ ).

\section{Discussion}

Decompressive craniectomy has been performed since the early 19 th century by neurosurgeons. Different types of bone

Table 1 Baseline characteristics of 81 patients with acute subdural hematoma

\begin{tabular}{|c|c|c|}
\hline Parameter & Group $1^{*}(N=58)$ & Group $2^{*}(N=23)$ \\
\hline \multicolumn{3}{|l|}{ Sex } \\
\hline Male & $81(47)$ & $82(19)$ \\
\hline \multirow[t]{2}{*}{ Female } & $19(11)$ & $17(4)$ \\
\hline & Mean age & \\
\hline Age & $40.9(13-77)$ & $44(16-74)$ \\
\hline \multicolumn{3}{|c|}{ Glasgow Coma Scale score at admission } \\
\hline $3-5$ & $41(24)$ & $54.5(12)$ \\
\hline $6-8$ & $55(32)$ & $45.5(10)$ \\
\hline \multicolumn{3}{|c|}{ Mechanism of head injury } \\
\hline Traffic accident & $55(32)$ & \\
\hline Fall accident & $39(23)$ & \\
\hline Others & $3.4(2)$ & \\
\hline \multicolumn{3}{|l|}{ Pupil reactivity } \\
\hline Both reacting & $24(14)$ & $21(5)$ \\
\hline 1 reacting & $56(33)$ & $69(16)$ \\
\hline Both non-reacting & $18(11)$ & $8(2)$ \\
\hline \multicolumn{3}{|c|}{ Glasgow Outcome Scale score within 30 days } \\
\hline 1 & $44.8(26)$ & $48(11)$ \\
\hline 2 & $3.4(2)$ & $9.5(2)$ \\
\hline 3 & $18.9(11)$ & $4.7(1)$ \\
\hline 4 & $25(15)$ & $19(4)$ \\
\hline 5 & $6.8(4)$ & $19(4)$ \\
\hline \multicolumn{3}{|l|}{ Midline shift } \\
\hline$>5 \mathrm{~mm}$ & $82.6(49)$ & $94.7(18)$ \\
\hline$<5 \mathrm{~mm}$ & $17.4(9)$ & $5.2(1)$ \\
\hline \multicolumn{3}{|l|}{ Cause of mortality } \\
\hline Brain swelling & $100(26)$ & $82(9)$ \\
\hline Total & 100 & 100 \\
\hline
\end{tabular}

Note: *Values are the number of patients expressed in percentages. decompression have been attempted with variations in the location and size of bone removal, depending on the cause of the ICP. ${ }^{13-15}$

Ransohoff and Benjamin, in 1971, gave an account of their experience with the management of an ASH demanding surgery for the preservation of life within the first 24 hours after injury. They mentioned a very high mortality for this type of head injury, which, in their own department, had previously reached $75 \%$. Very few patients were restored to normal life. Death had resulted from brain-stem compression, torsion, and secondary hemorrhage, but, at necropsy, few had shown what had been regarded as primary brain-stem lesions. ${ }^{5,13,16}$

The main question is: does every patient need decompressive craniectomy? Can we accurately predict who will need it? Decompressive craniectomy is not a procedure free of major complications, which include subdural effusions, hydrocephalus and syndrome of the trephined. ${ }^{11,17-21}$

Surgical evacuation by craniotomy is often considered in patients with an ASH thicker than $5 \mathrm{~mm}$ (as measured with an axial CT scan), who exhibit neurologic signs such as lethargy, change in mental status, or a focal neurologic deficit. Bullock et al reported that "an acute subdural hematoma with a thickness greater than $10 \mathrm{~mm}$, or a midline shift greater than $5 \mathrm{~mm}$ on CT scan, should be surgically evacuated, regardless of the patient's Glasgow Coma Scale (GCS) score.”6,9,18

Ongoing clinical trials on the use of decompressive craniectomy after TBI may clarify many aspects of the clinical application of this technique. However, some important pathophysiological issues, that is, the timing of DC, its effect on brain edema formation, and the role of secondary brain damage must be taken into consideration. ${ }^{8,22-24}$

Comparing with other studies, the prevalence of sex and mean age remains the same, as well as the etiology of trauma. The presence of a non-reacting pupillary abnormality was prevalent in both groups what makes similar groups on admission in relation to severity. ${ }^{2,3,10,25}$

Unilateral fronto-temporo-parietal hemicraniectomy was performed in 55 patients of Group 1 within 24 hours after the head trauma, and 3 patients were treated with delayed surgery. Two of them died, one from swelling and one from lung infection after a long time of hospitalization (27 days).

Taylor et $\mathrm{al}^{8}$ concluded that in children treated with a combination of very early DC (within 24 hours) and conventional medical management, it is more likely that ICP will be reduced, and fewer episodes of intracranial hypertension will occur, causing a better functional outcome and quality of life than the conventional management alone $(p=0.046){ }^{8}$ Similar results were achieved by Akyuz, ${ }^{2}$ who performed an early bilateral DC, as soon as possible, and obtained a decreased mortality rate and an improved favorable outcome. ${ }^{26-29}$

Primary DC is usually performed during the evacuation of an ASH, either because the brain is swollen, or because of the high risk of worsening of the brain swelling during the postoperative period. In a study conducted by Hartings et $\mathrm{al}^{30}$, ASH represents the most frequently operated type of mass lesion in the acute phase of TBI; an ASH was evacuated in 26 (87\%) out of 30 patients undergoing surgery for early evacuation of a mass lesion. ${ }^{31-33}$ 
In the present study, we could not find statistically significant differences in the mortality of both groups by Mann-Whitney test $(p=0.966)$. If the Glasgow Outcome Scale is included as comparative variable remains without statistical difference in 30 day analysis $(p=0.615)$. Extensive brain damage associated with an ASH is the main cause of death, like the contusion and swelling associated in $54.8 \%$ of cases. Even though mortality is similar in both groups, we need to seek harmonic clinical and surgical managements.

As evidenced by an IMPACT study, the prognosis in patients with mass lesions was better for patients with an epidural hematoma against the poor prognosis with an ASH, or partial obliteration of the basal cisterns or midline shift (> $5 \mathrm{~mm}) .{ }^{7}$ Who makes the decisions about the approach in relation to this mass lesion (ASDH) a hard task to be choose in the early hours of admission.

The mortality of patients younger than 50 years was $38 \%$, while for those older than 50 was $57 \%$. Moreover, the GCS score at admission presented an important relationship with mortality. A GCS score lower than 6 was associated with $67 \%$ mortality, while 7 and 8 caused a $25 \%$ death rate. As shown by Akyuz et al, the age and GCS score are major factors influencing DC effectiveness. It is generally assumed that the outcome of patients younger than 50 years or with an initial GCS score of 6 or more is significantly better than that of older patients or those with an initial GCS score lower than $6.2,25,26$

Ischemic brain damage affects outcome morbidity adversely, and the difficulty in preventing ischemic damage in cases with marked brain shift leads to poor outcomes in patients with ASHs. ${ }^{16,22,23}$

This study has several potential limitations. It was a retrospective review of preexisting data, and it suffers from the inherent limitations of such studies. Specifically, data collection through chart and imaging reviews is less complete and accurate than in a prospective study.

\section{Conclusion}

It is already known that urgent craniectomy with evacuation of the hematoma decreased mortality from $75 \%$ to $30 \%$ on severe TBI, but in ASH the mortality is still high. The evidence for the benefit of decompressive craniectomy was studied by comparing retrospectively two series of ASH, with and without DC. Based on our results, no apparent benefit could be attributed to DC in diminishing 30-day mortality. Therefore, a high GCS score at admission and age lower than 50 remain better outcome predictors for 30-day survival for patients undergoing surgery for a traumatic ASH.

\section{References}

1 Sener S, et al. Surgical Management of Traumatic Brain Injury Evidence, Controversies and Perspectives for the Future. Touch Briefings 2011

2 Akyuz M, Ucar T, Acikbas C, Kazan S, Yilmaz M, Tuncer R. Effect of early bilateral decompressive craniectomy on outcome for severe traumatic brain injury. Turk Neurosurg 2010;20(3):382-389
3 Huang YH, Lee TC, Lee TH, Liao CC, Sheehan J, Kwan AL. Thirty-day mortality in traumatically brain-injured patients undergoing decompressive craniectomy. J Neurosurg 2013;118(6):1329-1335

4 Bullock MR, Chesnut R, Ghajar J, et al; Surgical Management of Traumatic Brain Injury Author Group. Surgical management of acute subdural hematomas. Neurosurgery 2006;58(3, Suppl)S16-S24, discussion Si-iv

5 Cooper DJ, Rosenfeld JV, Murray L, et al; DECRA Trial Investigators; Australian and New Zealand Intensive Care Society Clinical Trials Group. Decompressive craniectomy in diffuse traumatic brain injury. N Engl J Med 2011;364(16):1493-1502

6 Plesnila N. Decompression craniectomy after traumatic brain injury: recent experimental results. Prog Brain Res 2007; 161:393-400

7 Murray GD, Butcher I, McHugh GS, et al. Multivariable prognostic analysis in traumatic brain injury: results from the IMPACT study. J Neurotrauma 2007;24(2):329-337

8 Taylor A, Butt W, Rosenfeld J, et al. A randomized trial of very early decompressive craniectomy in children with traumatic brain injury and sustained intracranial hypertension. Childs Nerv Syst 2001;17(3):154-162

9 Sahuquillo J, Arikan F. Decompressive craniectomy for the treatment of refractory high intracranial pressure in traumatic brain injury. Cochrane Database Syst Rev 2006;(1):CD003983

10 Oh CH, Shim YS, Yoon SH, Hyun D, Park H, Kim E. Early Decompression of Acute Subdural Hematoma for Postoperative Neurological Improvement: A Single Center Retrospective Review of 10 Years. Korean J Neurotrauma 2016;12(1):11-17

11 Stiver SI. Complications of decompressive craniectomy for traumatic brains injuriy. Neurosurg Focus 2009;26(6):E6

12 Torres R. DECRA...Where do we go from here? Surg Neurol Int 2012;3:54-55

13 Ransohoff J, Benjamin V. Hemicraniectomy in the treatment of acute subdural haematoma. J Neurol Neurosurg Psychiatry 1971; 34(1):106

14 Kjellberg RN, Prieto A Jr. Bifrontal decompressive craniotomy for massive cerebral edema. J Neurosurg 1971;34(4):488-493

15 Venes JL, Collins WF. Bifrontal decompressive craniectomy in the management of head trauma. J Neurosurg 1975;42(4):429-433

16 Abe M, Udono H, Tabuchi K, Uchino A, Yoshikai T, Taki K. Analysis of ischemic brain damage in cases of acute subdural hematomas. Surg Neurol 2003;59(6):464-472, discussion 472

17 Dashti SR, Baharvahdat H, Spetzler RF, et al. Operative intracranial infection following craniotomy. Neurosurg Focus 2008;24(6):E10

18 Miller JD. Surgical management of acute and chronic subdural hematoma. In: Schmidek HH, Sweet WH, eds. Operative Neurosurgical Techniques: Indications, Methods, Results. 2nd ed. Philadelpia: WB Saunders Co; 1998:33

19 Adamo MA, Drazin D, Waldman JB. Decompressive craniectomy and postoperative complication management in infants and toddlers with severe traumatic brain injuries. J Neurosurg Pediatr 2009;3(4):334-339

20 Ramakrishnan V, Dahlin R, Hariri O, et al. Anti-epileptic prophylaxis in traumatic brain injury: A retrospective analysis of patients undergoing craniotomy versus decompressive craniectomy. Surg Neurol Int 2015;6:8-12

21 Paredes I, Cicuendez M, Delgado MA, Martinez-Pérez R, Munarriz PM, Lagares A. Normal pressure subdural hygroma with mass effect as a complication of decompressive craniectomy. Surg Neurol Int 2011;2:88-92

22 Bor-Seng-Shu E, Figueiredo EG, Amorim RL, et al. Decompressive craniectomy: a meta-analysis of influences on intracranial pressure and cerebral perfusion pressure in the treatment of traumatic brain injury. J Neurosurg 2012;117(3):589-596

23 Takada D, Nagai H, Moritake K, Akiyama Y. Edema and elasticity of a fronto-temporal decompressive craniectomy. Surg Neurol Int 2012;3:11-30 
24 Kenning TJ, Gandhi RH, German JW. A comparison of hinge craniotomy and decompressive craniectomy for the treatment of malignant intracranial hypertension: early clinical and radiographic analysis. Neurosurg Focus 2009;26(6):E6

25 Kolias AG, Adams H, Timofeev I, et al. Decompressive craniectomy following traumatic brain injury: developing the evidence base. Br J Neurosurg 2016;30(2):246-250

26 De Bonis P, Pompucci A, Mangiola A, D’Alessandris QG, Rigante L, Anile C. Decompressive craniectomy for the treatment of traumatic brain injury: does an age limit exist? J Neurosurg 2010; 112(5):1150-1153

27 Appelboom G, Zoller SD, Piazza MA, et al. Traumatic brain injury in pediatric patients: evidence for the effectiveness of decompressive surgery. Neurosurg Focus 2011;31(5):E5

28 Kan P, Amini A, Hansen K, et al. Outcomes after decompressive craniectomy for severe traumatic brain injury in children. J Neurosurg 2006;105(5, Suppl)337-342
29 Patel N, West M, Wurster J, Tillman C. Pediatric traumatic brain injuries treated with decompressive craniectomy. Surg Neurol Int 2013;4:128-149

30 Hartings JA, Vidgeon S, Strong AJ, et al; Co-Operative Studies on Brain Injury Depolarizations. Surgical management of traumatic brain injury: a comparative-effectiveness study of 2 centers. J Neurosurg 2014;120(2):434-446

31 Hayes SB, Benveniste RJ, Morcos JJ, Aziz-Sultan MA, Elhammady MS. Retrospective comparison of craniotomy and decompressive craniectomy for surgical evacuation of nontraumatic, supratentorial intracerebral hemorrhage. Neurosurg Focus 2013;34(5):E3

32 Takeuchi S, Wada K, Nagatani K, Otani N, Mori K. Decompressive hemicraniectomy for spontaneous intracerebral hemorrhage. Neurosurg Focus 2013;34(5):E5

33 Alvis-Miranda H, Castellar-Leones SM, Moscote-Salazar LR. Decompressive Craniectomy and Traumatic Brain Injury: A Review. Bull Emerg Trauma 2013;1(2):60-68 